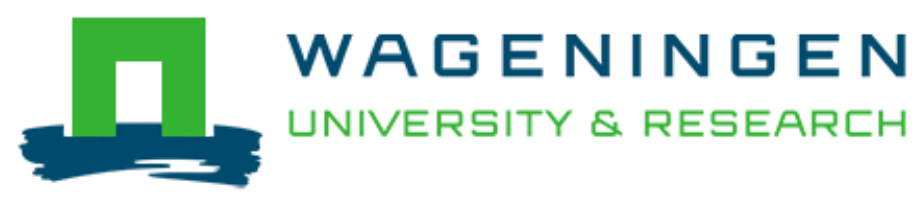

Theory of membrane capacitive deionization including the effect of the electrode pore space

Biesheuvel, P. M., Zhao, R., Porada, S., \& van der Wal, A.

This is a "Post-Print" accepted manuscript, which has been published in "Journal of Colloid and Interface Science"

This version is distributed under a non-commercial no derivatives Creative Commons

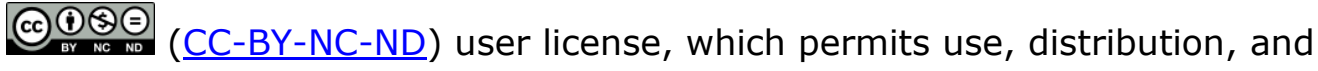
reproduction in any medium, provided the original work is properly cited and not used for commercial purposes. Further, the restriction applies that if you remix, transform, or build upon the material, you may not distribute the modified material.

Please cite this publication as follows:

Biesheuvel, P. M., Zhao, R., Porada, S., \& van der Wal, A. (2011). Theory of membrane capacitive deionization including the effect of the electrode pore space. Journal of Colloid and Interface Science, 360(1), 239-248.

https://doi.org/10.1016/j.jcis.2011.04.049 


\title{
Theory of Membrane Capacitive Deionization including the effect of the electrode pore space
}

\author{
P.M. Biesheuvel ${ }^{1,2, *}$ R. Zhao, ${ }^{1,2}$ S. Porada, ${ }^{2,3}$ and A. van der Wal ${ }^{4}$
}

${ }^{1}$ Department of Environmental Technology, Wageningen University, Bornse Weilanden 9, 6708 WG Wageningen, The Netherlands. ${ }^{2}$ Wetsus, centre of excellence for sustainable water technology, Agora 1, 8900 CC Leeuwarden, The Netherlands. ${ }^{3}$ Department of Polymers and Carbon Materials, Faculty of Chemistry, Wroclaw University of Technology, Wybrzeze Wyspianskiego 27, 50-370 Wroclaw, Poland. ${ }^{4}$ Voltea B.V., Wasbeekerlaan 24, 2171 AE Sassenheim, the Netherlands. *E-mail: maarten.biesheuvel@wur.nl.

\section{Abstract}

Membrane capacitive deionization (MCDI) is a technology for water desalination based on applying an electrical field between two oppositely placed porous electrodes. Ions are removed from the water flowing through a channel in between the electrodes and are stored inside the electrodes. Ionexchange membranes are placed in front of the electrodes allowing for counterion transfer from the channel into the electrode, while retaining the coions inside the electrode structure. We set up an extended theory for MCDI which includes in the description for the porous electrodes not only the electrostatic double layers (EDLs) formed inside the porous (carbon) particles, but also incorporates the role of the transport pathways in the elctrode, i.e., the interparticle pore space. Because in MCDI the coions are inhibited from leaving the electrode region, the interparticle porosity becomes available as a reservoir to store salt, thereby increasing the total salt storage capacity of the porous electrode. A second advantage of MCDI is that during ion desorption (ion release) the voltage can be reversed. In that case the interparticle porosity can be depleted of counterions, thereby increasing the salt uptake capacity and rate in the next cycle. In this work, we compare both experimentally and theoretically adsorption/desorption cycles of MCDI for desorption at zero voltage as well as for reversed voltage, and compare with results for CDI. To describe the EDL-structure a novel modified Donnan model is proposed valid for small pores relative to the Debye length.

\section{Introduction}

Providing for clean water in a safe, inexpensive and energy-efficient manner is amongst the most important technological challenges facing humanity the coming decades. ${ }^{1-3}$ Desalination is a key requirement to convert brackish, sea or waste water into water suitable for use. Presently, reverse osmosis and distillation are the state-of-the-art technologies for large-scale desalination. In these approaches, clean water is produced either by using water-permeable membranes, or by evaporation. Desalination using these techniques can be energetically demanding and especially for water of relatively low ionic strength, it can be advantageous not to focus on the recovery of clean water from the salt-containing solution, as in reverse osmosis and distillation, but instead to focus on removing the relatively few ions. In this respect it is interesting to note that at $10 \mathrm{mM}$, which is approximately the lower limit of brackish water, for each 2500 water molecules there is only about one ion.

This approach, to focus on the removal of the ions from the solution that must be treated, is followed in electrodialysis ${ }^{4,5}$ and in capacitive deionization (CDI). ${ }^{6-23}$ In the present work we focus on CDIrelated techniques. CDI is a technology where an electrical field is applied between two closely spaced porous electrodes (often activated carbon with internal surface areas of the order of 
$1000 \mathrm{~m}^{2} / \mathrm{g}$; a typical cell voltage is $1.2 \mathrm{~V}$ ). lons in the water flowing through the transport channel, or "spacer", in between the electrodes, are extracted, with cations stored in the cathode (the electrode of negative electrical bias) and anions stored in the other electrode, with the effluent water desalinated to a certain degree. The assembly of electrodes and transport channel is called a "cell". CDI is a technology similar to that of electrostatic double layer (EDL) supercapacitors ${ }^{23,24,25}$ but modified to operate in a "flowthrough"-mode, while focus is on salt removal and not on charge storage. Also laminar flow fuel cells use such a flowthrough mode but focus on electrochemical conversion. ${ }^{26}$ In CDI, ions removed from the inflowing solution are stored in the EDLs within the porous electrode, and when the ion storage capacity is reached (or a certain percentage thereof), the applied voltage can be reduced and ions are again released leading to a (small) product stream concentrated in salt.
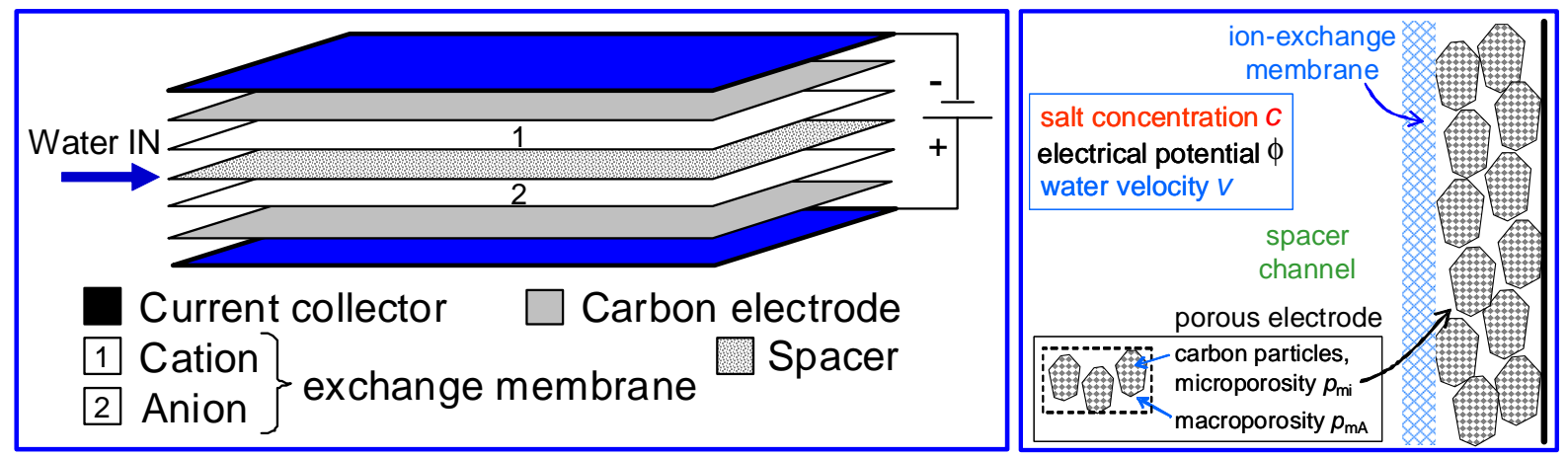

Fig. 1. Membrane capacitive deionization (MCDI). Influenced by the electrical field, cations present in the water flowing through the spacer channel migrate through the cation exchange membrane and are stored inside the adjacent porous electrode; simultaneously, anions are stored in the opposite electrode. In CDI, the ion exchange membranes are left out. Schematic overview of (a) one cell, and (b) modeling approach for an electrode consisting of porous carbon particles.

CDI (and MCDI, to be discussed below) are electro-capacitive processes, implying that electrochemistry does (ideally) not occur, with charge storage of a purely capacitive nature, and thus the process being repeatable without energetic losses. The size scale of our cells is typically of the order of $100-$ $200 \mu \mathrm{m}$ thickness for each layer (which are spacers, membranes, electrodes, and current collectors), making a complete cell typically of the order of $1 \mathrm{~mm}$ thickness. Therefore, $(\mathrm{M}) \mathrm{CDI}$ is an example of a "millifluidic" flow technology. In CDI, the electron current that goes from anode to cathode during ion adsorption is reversed during ion release, with ideally a perfect charge balance, i.e., integrated over a complete cycle of ion adsorption and desorption, there is no leakage current due to electrochemical reactions. ${ }^{27,28}$ An external power source charges the CDI-cell during the ion adsorption-step, i.e., energy is required to transfer electrons from the anode to the cathode, while during ion release (ion desorption) the electrons spontaneously flow in the reverse direction. During this stage, the electron current can be used to partially charge another CDI-cell during its ion adsorption step. In this way the overall energy consumption of a desalination stack consisting of multiple cells, can be reduced. It is the general aim to find operation schemes for CDI where the total energy use is as close as possible to the thermodynamic minimum energy input for desalination, which is for a $1: 1$ salt given by $\Delta G_{\min }=2 R T\left(c_{\text {in }}-c_{\mathrm{d}}\right) \cdot\left[\frac{\ln \alpha}{1-\alpha}-\frac{\ln \beta}{1-\beta}\right]$ per volume of dilute product (of salt concentration $c_{\mathrm{d}}$, while the 
inflow has a salt concentration $c_{\text {in }}$, and the concentrate $c_{\mathrm{c}}$ ), where $\alpha=c_{\mathrm{in}} / c_{\mathrm{d}}$ and $\beta=c_{\text {in }} / c_{\mathrm{c}}$, an expression valid for ideal thermodynamic conditions. ${ }^{4,13}$ The recovery, being the ratio of dilute product volume to inlet volume, $r$, relates to salt concentrations according to $r=\left(c_{\mathrm{c}}-C_{\mathrm{in}}\right) /\left(C_{\mathrm{c}}-C_{\mathrm{d}}\right)$.

It has been found experimentally that positioning ion-exchange membranes in front of the electrodes improves performance of the CDI-process significantly. In this approach, called membrane capacitive deionization (MCDI), see Fig. 1, cation exchange membranes are placed in front of the cathode, i.e., the electrode which during the ion-removal step attracts the cations by applying a negative voltage relative to the other electrode, which is the anode and which attracts the anions. ${ }^{29-35}$ The origin of the advantageous effect of the membranes is not completely understood, which hampers further optimization of this technology. The only previous theoretical model for MCDI (ref. 32) considers that the ions are adsorbed in the EDLs which are formed inside the carbon particles where the electrolyte contacts the carbon matrix, without considering a possible salt storage in the interparticle pore space or transport pathways in the electrode (which we call macropores as in ref. 7 , with the pores inside the carbon called the micropores ${ }^{7,36,37}$ ). However, co-ions expelled from the EDLs inside the particles will end up in these macropores. Because of charge neutrality there, more counterions can then be absorbed in the electrode. In the present work we will include the macropores in the theoretical model, and show that we are well able to describe experimental data for CDI and MCDI. Thus, the novel theoretical model is suitable for predictive purposes such as for system optimization.

The $(M) C D I$ transport model describes how the ion current across the membrane into the electrode leads to a simultaneous electron current to keep charge balance in the electrode. The ion current is mainly due to counterion transport, but for non-ideal membranes also has a contribution from coions going in the reverse direction. Note that the counterions are the ions that during the ion removal-step are attracted into the electrode; thus cations are counterions in the cathode, and vice-versa for anions in the anode. The co-ion is the ion that during ion removal is depleted from the EDLs in the micropores. The electron current will be charge-balanced partially by counterion adsorption from the interparticle pore space (macropores, where the concentration of cations equals that of the anions) into the EDLs which are formed inside the micropores, and partially by the desorption of co-ions from the EDLs. These co-ions are largely retained by the membrane and thus accumulate in the interparticle pore space, increasing the concentration to values beyond that in the spacer channel. Because of charge neutrality in the macropores, this accumulation of co-ions also leads to an accumulation of counterions. Thus, effectively, part of the transported counterions (from the spacer channel through the membrane) is adsorbed in the EDLs in the micropores, and part is stored in the macropores. Therefore, the macropores play an important role in increasing the salt adsorption efficiency of MCDI, an effect which is absent in CDI because in CDI the salt concentration in the macropores is lower during ion-removal (not higher) while upon reaching equilibrium it becomes the same as the salt concentration outside the electrode, i.e., in the spacer channel, and thus the macropores have no salt storage capacity in CDI.

A further advantage of MCDI is that it is possible to operate at reversed voltage during ion release. This is not possible in CDI (the technology without membranes) because then the ions that are released from the one electrode are quickly adsorbed in the other electrode, without releasing much 
salt into the effluent stream, i.e., the role of cathode and anode is simply reversed. In MCDI, the counterions are released from one electrode into the spacer channel, but cannot move into the other electrode because of the membrane. Thus both electrodes are depleted of their respective counterions. Not only are counterions removed to the point that the electrode is charge neutral again, but counterion desorption continues, first of all from the EDLs in the micropores, in which now the coions are attracted as countercharge, and secondly from the interparticle macropores, of which the salt concentration drops dramatically. Thus we have a very effective clean-up of the counterions from the electrode structure. Consequently, in the subsequent adsorption step of the next cycle, the counterion adsorption rate and capacity are significantly increased compared to CDI.

In the next sections we will introduce the various theoretical elements of the improved MCDI-model which includes the above effects, list the various assumptions, present the mathematical framework to calculate desalination performance and electrical currents, and compare model predictions with experimental data for $\mathrm{CDI}$ and for MCDI in two operating modes: both for ion release at zero voltage ("O-MCDI"), and for ion release at reversed voltage ("r-MCDI").

\section{General discussion of theory for MCDI}

In this section we introduce the elements of the theoretical process model which can be used both for MCDI and CDI. We will describe the modifications relative to the theory of ref. 32, and list the various assumptions that are made.

- As discussed in the previous section, the theory distinguishes between the interparticle pores (the macropores in between the carbon particles) where $c_{\text {cation }}=C_{\text {anion, }}$, and the micropores inside the carbon particles, where the concentration of the cations and anions can be different, i.e., EDLs are formed. 7,36,37,38 The pore volume inside the carbon particles (intraparticle porosity), we call the microporosity, $p_{\mathrm{mi}}$, while the pores outside, i.e., in between, the carbon particles is the interparticle, or macro-porosity, $p_{\mathrm{mA}}$. Formally, micropores and macropores are defined as those pores with sizes $<2 \mathrm{~nm}$ and $>50 \mathrm{~nm}$, respectively, but we follow literature on porous electrode transport theory ${ }^{7}$ where microporosity is used for the pores inside the carbon particles, and macroporosity for the much larger, transport, pores, outside the carbon particle.

- Transport of ions through the ion-exchange membrane in front of the electrode will be described using the Nernst-Planck equation allowing for both types of ions to permeate the membrane. ${ }^{39,40,41}$ Thus, the membranes are not considered to be ideally permselective as in ref. 32 . We will exclude transport of protons or hydroxyl-ions and also set a possible water flow through the membrane to zero.

- At the membrane-solution edges Donnan-equilibrium is assumed which relates the ion concentration difference across each of these edges to the voltage drop (Donnan potential).

- Transport in the spacer channel is described in the flow direction $(y)$ by considering several idealstirred volumes placed in series, like our approach in ref. 32. Each stirred-volume is defined by a single salt concentration, i.e., we neglect a salt concentration gradient in the direction of the membrane. This is different from our approach in ref. 32 where we made use of the concept of an equilibrium Nernst layer (stagnant boundary layer, diffusion film, mass transfer layer, concentration-polarization layer), a thin theoretical layer envisioned in front of the membrane, separating the membrane from the 
spacer channel bulk volume, see refs. $[21,32,42,43]$. In hindsight, this approach is problematic in MCDI because the spacer channel is already quite thin, and thus a theoretical separation of the channel into a bulk-phase and two diffusion films, is not well possible (actually, the spacer thickness is of the order of a typical thickness of such a diffusion film, about $200 \mu \mathrm{m}$ ). Furthermore, full calculations using the Nernst-Planck equation showed that because our spacer channel is thin, and because a significant part of the ion transport resistance is located within the electrode, concentration variations across the spacer channel (in $x$-direction) are not that significant. Note that this is different in electrodialysis where mass transfer resistances are mainly in the flow channel. ${ }^{5}$ Thus, across the thickness of the spacer channel in $x$-direction we consider a constant salt concentration (which depends on time, and on $y$-position) and thus we arrive at an expression for the ion current $J$ in $x$-direction which is linear with the salt diffusion coefficient and the spacer salt concentration, $c_{\mathrm{sp}}$.

- Within the porous electrode we do not use the full nonlinear porous electrode theory for desalination described in refs. 21 and 28, but use a simplified approach in which we average the concentrations across the electrode region (i.e., neglect salt concentration and potential gradients in the macropores), as in ref. 44, and describe the transport resistance empirically by considering an electrical resistance which is linearly dependent on the macropore salt concentration, $c_{\mathrm{mA}}$, analogous to the description of the resistance in the spacer channel.

- Addiitionally, for the electrode region we include the possibility that there is a small convective leakage flow of solution through the electrodes, on the "wrong side" of the membrane, entering the electrode "head-on", see ref. 44 where this effect is considered for the first time, in the context of energy recovery from the sequential flow of sea and river water through a millifluidic device.

- To describe the EDLs we previously made use of the Gouy-Chapman-Stern (GCS) model, see refs. $[13,15,20,21,28,32,44,45,46]$. The GCS-model was shown to be very successful in describing equilibrium data for both salt adsorption and charge density in porous electrodes as function of cell voltage and ionic strength. However, in the course of modeling transport into porous electrodes, we found that the GCS-model is problematic, and cannot be used robustly in a transport model where the macropore salt concentration, $c_{\mathrm{mA}}$, changes in time and when the pore size is small relative to the Debye length. This relates to the fact that the GCS-model assumes a diffuse layer (besides an inner, Stern, layer) which has a typical extension into free solution of several times the Debye length (which is $\sim 3 \mathrm{~nm}$ at $10 \mathrm{mM}$ salt concentration). However, the micropores in porous activated carbon electrodes are small (less than $2 \mathrm{~nm}$ ) and diffuse layers must be overlapping strongly. ${ }^{47,48,49}$ Using the GCSmodel in a transport model, especially in modeling MCDI at reversed voltage during ion release, where $c_{\mathrm{mA}}$ goes down strongly, leads to mathematical divergences. This led us to develop a novel approach which is presented here; namely, we describe the interior volume of the carbon particle by a "modified Donnan model". In this model it is assumed that within the carbon particle the pore space has an approximately constant electrostatic potential. This is a reasonable assumption because the Debye length is in most situations much larger than the micropore size. Compared to the classical Donnan approach used for charged gels, membranes, sedimentation of charged colloids, ${ }^{50}$ clays $^{37,38}$ and porous electrodes, ${ }^{51}$ we make two modifications: firstly, we include the charge-free Stern layer in between the pore solution and the carbon matrix, and secondly we consider an additional attractive force 
for the ion to go from the macropores into the micropores, described by a chemical attraction of strength $\mu_{\text {att }}$. In this way it will be possible to include in the model the fact that even at zero voltage, neutral salt already adsorbs in the carbon material. This adjustment is also required because as shown in Fig. 2 (to be discussed further on) we measure a much higher co-ion expulsion from the carbon particles than can be explained in the absence of the chemical attraction (i.e., for $\mu_{\text {att }}=0$ ). In the present work we use for the cation and the anion the same value for $\mu_{\text {att }}$ to preserve symmetry between the two electrodes in the theory, but it is more likely that in reality the two numbers are different for each ion, and will also be different for different ions of the same sign. ${ }^{52}$

- To make the EDL adsorption properties in the carbon particles more intuitively insightful, we no longer describe the EDL-properties per unit surface area of the electrolyte/carbon interface, but define the salt adsorption and charge as a concentration per unit volume of intraparticle pore space (i.e., based on the micropore volume within the carbon particles). Assuming perfect symmetry of the two electrodes, we can then derive the concentration of counterions and co-ions in the micropores (relative to that at zero applied cell voltage) from measured salt adsorption and charge in a CDI-cell, see Fig. 2a. A similar graph is given as fig. 2 in ref. 8 .
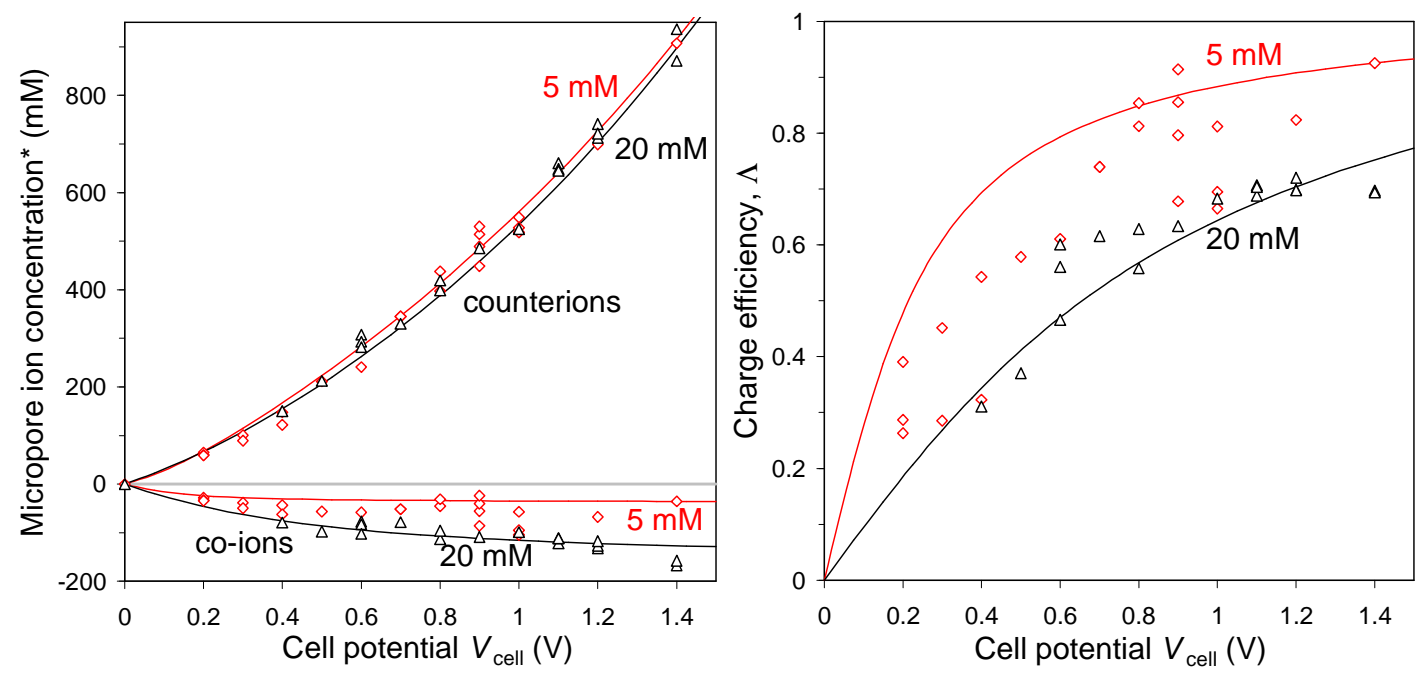

Fig. 2. Equilibrium data for capacitive deionizaton. (a) Concentration of counterions and coions in porous carbon micropores, and (b) charge efficiency. Data as function of cell potential and $\mathrm{NaCl}$ salt concentration (red diamonds: $5 \mathrm{mM}$; black triangles: $20 \mathrm{mM})\left(p_{\text {micro }}=37\right.$ vol\%, $\mu_{\text {att }}=2 \mathrm{kT}$, $C_{\mathrm{St}}=C_{\mathrm{St}, 0}+\alpha \cdot \Delta \phi_{\mathrm{St}}{ }^{2}$ where $C_{\mathrm{St}, 0}=0.12 \mathrm{~F} / \mathrm{m}^{2}$ and $\left.\alpha=5 \cdot 10^{-5} \mathrm{~F} / \mathrm{m}^{2}\right)$. Theoretical curves are based on Eqs. 11-14. In (a) concentrations are given per unit micropore volume, relative to the adsorption at zero cell voltage.

For the co-ions we observe in Fig. 2 that the concentration (relative to zero voltage) is negative, which is as expected, because the co-ion is expelled from the EDLs. But, unexpectedly this co-ion concentration is in magnitude much larger (namely up to values of the order of $150 \mathrm{mM}$ ) than the expected pore concentration at zero voltage (which is equal to the concentration in the spacer channel in these equilibrium experiments, either 5 or $20 \mathrm{mM}$ for the data of Fig. 2). This is a very remarkable finding, which may prove to be an important piece of information in finding a proper EDL-model for porous electrodes in contact with aqueous solutions. We interpret these highly negative co-ion concentrations as being due to the fact that also without applying a cell voltage, there is salt adsorption in the porous 
carbon particles due to a chemical affinity of the ions with the porous carbon. Upon applying the voltage, the co-ions of these chemically adsorbed salt molecules are expelled. This effect will be included using non-zero values of the attractive term $\mu_{\text {att. }}$. This assumption of a chemical attraction of ions into the micropores of activated carbon particles is supported by the fact that porous carbons are wellknown to adsorb ions, also in the absence of an applied voltage.

- In this work we assume perfect symmetry in the cell: the membranes are either in front of both electrodes, or in front of neither electrode (which is CDI). Both membranes are assumed to have the same ion mobility and to have the same membrane fixed charge density, $X$. Note that experimentally it is certainly possible to place an ion-exchange membrane only in front of one membrane, and have water desalination, as reported in ref. 33 and 34. Furthermore we assume an equal mass of the anode and cathode, and a symmetrical structure of the EDL, i.e., the EDL-structure in the anode is completely similar to that in the cathode (except for the difference in charge sign). We take the same diffusion coefficient for both ions, both in solution (the spacer channel) and in the membrane.

- We do not consider a possible role of protons and hydroxyl ions in determining the structure of the EDL, e.g. by modifying the chemical surface charge of the carbon. We consider a monovalent 1:1 salt solution of ions that are fully dissociated, like $\mathrm{NaCl}$. We neglect possible faradaic, electrochemical, reactions in the electrodes.

\section{Mathematical description of theory}

In this section we present the mathematical model for the MCDI and CDI process, based on the elements and assumptions explained in the previous section. We start with discussing ion transport in the spacer, then the membrane, and finally describe ion storage in the porous electrode as a whole, as well as in the EDLs within the porous particles.

\section{Transport in the spacer and membrane}

For the spacer channel we set up a salt mass balance in which the accumulation of salt is determined by diffusion and migration in the $x$-direction into the membrane (or for CDI directly into the electrode), and by convective flow in the axial, or $y$-, direction through the spacer channel, given by

$\frac{\partial c_{\mathrm{sp}}(y)}{\partial t}=-\frac{J_{\text {ion }}(y)}{\delta_{\mathrm{sp}}}-v_{\mathrm{sp}} \frac{\partial c_{\mathrm{sp}}(y)}{\partial y}$

where $c_{\text {sp }}$ is the spacer salt concentration in $\mathrm{mol} / \mathrm{m}^{3}(\mathrm{mM}), t$ is time, $J_{\text {ion }}$ the ion flux in $x$-direction at one interface directed into the membrane or electrode (in a perfectly symmetric cell $J_{\text {ion }}$ is the same in magnitude on each interface, and thus equal to the salt flux from the transport channel; note that we consider a 1:1 salt thus two ions constitute one salt molecule), $v_{\mathrm{sp}}$ the spacer water velocity, and $y$ the coordinate along the length of the channel from $y=0$ at the entrance to $y=L$ at the exit of the channel.

In using Eq. 1, we make several assumptions: 1. we neglect axial diffusion, or dispersion in the $y$ direction, and 2. we consider concentration gradients in the $x$-direction to be small. Both these assumption become the more valid the more the cell length $L$ exceeds the channel width, $\delta_{\mathrm{sp}}$, a condition typically well met in an (M)CDI flow-cell (e.g. $5 \mathrm{~cm}$ for $L$ vs. $200 \mu \mathrm{m}$ for $\left.\delta_{\mathrm{sp}}\right)$. The velocity, $v_{\mathrm{sp}}$, is given 
by $v_{\mathrm{sp}}=\Phi_{\mathrm{sp}} \cdot L / V_{\mathrm{sp}}$ where $\Phi_{\mathrm{sp}}$ is the water flow rate through the spacer channel (volume/time), $L$ is the length (in $y$-direction) of the channel and $V_{\mathrm{sp}}$ is the spacer channel volume.

The ion current density $I$ in $x$-direction (flux of cations minus flux of anions) is invariant with $x$ (also constant across the solution/membrane interfaces, and across the membrane; but it does depend on $y$ ). In the spacer channel, assuming absence of concentration gradients in $x$-direction, and for equal ion diffusion coefficients, the current $I$ depends on the electrical potential difference across the spacer channel half-space (from midplane to edge), $\Delta \phi_{\mathrm{sp}, \text { half, }}$ according to ${ }^{5}$

$$
I(y)=-2 D \cdot c_{\mathrm{sp}}(y) \cdot \frac{\Delta \phi_{\mathrm{sp}, \mathrm{half}}(y)}{h}
$$

where $\phi$ is nondimensional and can be multiplied by the thermal voltage, $V_{T}=R T / F(\sim 25.6 \mathrm{mV})$, to arrive at a voltage with dimension Volt, and where $h=\delta_{\mathrm{sp}} / 2$. Current $/$ has dimension of moles/area/time, and can be multiplied by Faraday's number, $F$, and integrated over the membrane area $A$ to obtain a total cell current with dimension Ampère. The diffusion coefficient $D$ is the average of that of the anion and the cation. ${ }^{5}$

At the two membrane/solution interfaces we have Donnan equilibrium, both on the edge of the membrane with the spacer channel, and on the edge of the membrane with the electrode. These two Donnan potentials are given by ${ }^{53,54}$

$\Delta \phi_{\text {donnan }}=\sinh ^{-1} \frac{\omega X}{2 c_{\text {salt }}}$

where $c_{\text {salt }}$ is the salt concentration just outside the membrane (being either $c_{\mathrm{sp}}$, or the macropore salt concentration in the electrode, $\left.c_{\mathrm{mA}}\right), X$ is the membrane 'ion exchange capacity', i.e., the magnitude of the membrane fixed charge density, and $\omega$ is the sign of the membrane charge (e.g., $\omega=+1$ for an anion-exchange membrane).

Inside the membrane, charge balance is given by $c_{\text {cation }}-C_{\text {anion }}+\omega X=0$ which can be combined with the Nernst-Planck (NP) equation for each ion, and the resulting set of equations can be solved exactly. ${ }^{5,41}$ However, because full calculations showed that the concentration and potential profiles across the membrane are close to linear in a highly charged membrane, we linearize the NP-equations leading for current $/$ to

$$
I(y)=-\frac{D_{\text {mem }}}{\delta_{\text {mem }}}\left\langle c_{\text {T,mem }}(y)\right\rangle \Delta \phi_{\text {mem }}(y)
$$

where subscript "mem" is used for properties within the membrane, where $c_{T, m e m}$ is the total ion concentration in the membrane, given by $c_{\mathrm{T}, \mathrm{mem}}=c_{\text {cation,mem }}+c_{\text {anion,mem, }}$, where $<. .>$ denotes an average property, where $\Delta$ is the difference across the membrane, and where $\delta_{\text {mem }}$ is the membrane thickness. At both solution/membrane edges, the total ion concentration in the membrane, $c_{T, m e m}$, is given by $c_{\mathrm{T}, \mathrm{mem}}=2 \cdot c_{\mathrm{salt}} \cdot \cosh \left(\Delta \phi_{\text {donnan }}\right)=\sqrt{ }\left(X^{2}+\left(2 \cdot c_{\text {salt }}\right)^{2}\right)$, with $c_{\text {salt }}$ as for Eq. 3 either $c_{\mathrm{sp}}$ or $c_{\mathrm{mA}}$. The average concentration $<c_{T, \text { mem }}>$ required in Eq. 4 is calculated as the average of these two boundary values for $c_{T, m e m}$. Likewise, the linearized total ion flux through the membrane, $J_{\text {ion,mem }}$, is given by

$$
J_{\text {ion,mem }}(y)=-\frac{D_{\text {mem }}}{\delta_{\text {mem }}}\left(\Delta C_{\text {T,mem }}(y)-\omega X \Delta \phi_{\text {mem }}(y)\right) \text {. }
$$


In this linearized membrane-model we assume that the ion flux is constant across the membrane, and related, that there is no accumulation of salt in the membrane. Full calculations, however, based on the full NP-equation for the membrane, implemented in a differential mass balance, show that this is not exactly true, and that there can be differences in $\mathrm{J}_{\text {ion,mem }}$ across the membrane (especially upon voltage reversal in r-MCDI), leading to salt storage or depletion of the membrane itself. This model extension, however, is not further considered in the present work.

For the linearized model, the ion flux through the membrane $J_{\text {ion,mem, }}$ is equal to the ion fluxes in solution at the two solution/membrane edges. On the side of the spacer channel, Jion,mem goes directly into Eq. 1, while on the side of the electrode, it enters in the electrode ion balance, Eq. 10. The current density in the membrane, I, given by Eq. 4, equals the current density in the spacer channel, given by Eq. 2, and is equal to the current that runs into the micropores within the electrode, see Eq. 9. These are the boundary conditions which apply in the $x$-direction. In the axial $y$-direction, we only have to prescribe the inflowing concentration $c_{\mathrm{sp}}(y=0)=c_{\text {in }}$.

We solve Eq. 1 by discretization into $M$ ideally-stirred volumes placed in series, like in ref. 32 . In that case, Eq. 1 can be simplified to:

$\frac{\partial c_{\mathrm{sp}, \mathrm{i}}}{\partial t}=-\frac{J_{\mathrm{ion}, \mathrm{i}}}{\delta_{\mathrm{sp}}}-\frac{M}{\tau_{\mathrm{sp}}}\left(c_{\mathrm{sp}, \mathrm{i}}-c_{\mathrm{sp}, \mathrm{i}-1}\right)$

where $\mathrm{i}$ is a counter running from 1 for the first volume to $M$, the last, and $\tau$ is the spacer channel residence time (spacer channel volume $V_{\mathrm{sp}}=A \cdot \delta_{\mathrm{sp}}$, divided by the water flow rate $\Phi_{\mathrm{sp}}$ ). The inflow salt concentration into the cell is $c_{\mathrm{in}}=c_{\mathrm{sp}, 0}$ and the eflluent or outflow salt concentration is $c_{\mathrm{eff}}=c_{\mathrm{sp}, \mathrm{M}}$. All of the following equations in this section are solved for each stirred volume $(1<i<M)$ separately.

Finally, we consider the voltage across the cell which is given by the sum of the potential drop over each spacer channel half-space (from 0 to $h$ ), $\Delta \phi_{\text {sp,half, }}$, the Donnan potential, $\Delta \phi_{\text {donnan }}$, at the membrane/spacer edge, the potential across the membrane, $\Delta \phi_{\text {mem }}$, minus $\Delta \phi_{\text {donnan }}$ at the membrane/electrode edge, the potential drop in the electrode, $\Delta \phi_{\text {elec }}$, and the Donnan potential and the Stern layer potential in the micropores, $\Delta \phi_{\mathrm{d}}+\Delta \phi_{\mathrm{St}}$, to be discussed further on, together sum up to half of $V_{\text {cell }} / V_{\mathrm{T}}$, where $V_{\text {cell }}$ is the cell voltage, i.e. the voltage applied between the two electrodes, $V_{\text {cell }}=V_{\text {anode }}-V_{\text {cathode }}$. This can be summarized as

$\frac{1}{2} V_{\text {cell }} / V_{\mathrm{T}}=\Delta \phi_{\mathrm{sp}, \text { half }}+\Delta \phi_{\text {donnan,membrane/spacer }}+\Delta \phi_{\text {mem }}-\Delta \phi_{\text {donnan,membrane/lectrode }}+\Delta \phi_{\text {elec }}+\left(\Delta \phi_{\mathrm{d}}+\Delta \phi_{\mathrm{St}}\right)_{\text {micropores }}$

where the electrode potential drop, $\Delta \phi_{\text {elec }}$ relates to current density I according to

$\Delta \phi_{\text {elec }} \cdot V_{\mathrm{T}}=-I \cdot F \cdot R_{\text {elec }} / C_{\text {mA }}$

with $R_{\text {elec }}$ an electrode specific resistance with dimension $\Omega . \mathrm{mol} / \mathrm{m}$.

The above model can be used both for MCDI and for CDI. For CDI, the membrane is absent, which can be modelled simply by setting the membrane thickness $\delta_{\text {mem }}$ equal to zero. This is sufficient, but in our calculations we also set the membrane charge to zero, i.e., $X=0$. In CDI this means that the concentration in the spacer channel at the edge with the (now vanished) membrane becomes equal to the concentration in the electrode macropores, $c_{\mathrm{mA}}$. 


\section{Electrodes and electrostatic double layers}

Within the electrodes, we do not consider in the $x$-direction any gradients in potential, $\phi$, and concentration, $c$, but take an average value for $\phi$ and $c$. Detailed theory to describe ion migration and diffusion across a porous electrode, and thus the resulting gradients in $\phi$ and $c$, is given in refs. 21 and 28. In the electrode, there are two different porous (electrolyte-filled) phases. First of all, there are the macropores, where we assume $c_{\text {cation }}=c_{\text {anion, }}$, which equals the macropore salt concentration, given by $c_{\mathrm{mA}}$. This is the volume in between the carbon particles, and has porosity $p_{\mathrm{mA}}$ (equal to $p_{\mathrm{M}}$ in ref. 7 ). Secondly, we consider the micropores with porosity $p_{\mathrm{mi}}$, in which the cat- and anion concentrations, $c_{i, m i}$, can be different from one another, which we will determine using the modified Donnan model as will be explained next. The porosities $p_{\mathrm{mA}}$ and $p_{\mathrm{mi}}$ are defined as pore volumes per unit total electrode volume, with the macropore salt concentration $c_{\mathrm{mA}}$ defined per unit macropore volume, and the ion concentrations in the micropores, $c_{\mathrm{i}, \mathrm{mi}}$, defined per unit of micropore volume. Note that $p_{\mathrm{mi}}$ is not the same as $p_{\mu}$ in ref. 7 where $p_{\mu}$ is the micropore volume relative to the volume of the carbon particles.

The first electrode balance describes how the "charge concentration" in the micropores, $C_{\text {charge,mi }}=C_{\text {cation,mi }}-C_{\text {anion,mi }}$, relates to the current density $I$ (defined on the projected area of the electrode, $A$ ) according to

$\frac{\mathrm{d}}{\mathrm{d} t}\left(p_{\mathrm{mi}} \cdot c_{\text {charge, mi, }}\right)=\frac{l_{\mathrm{i}}}{\delta_{\text {elec }}}$

where $\delta_{\text {elec }}$ is the electrode thickness.

The second electrode balance relates the membrane ion flux, $J_{\text {ion }}$, to the total ion concentration in the electrode,

$$
\frac{\mathrm{d}}{\mathrm{d} t}\left(2 \cdot p_{\mathrm{mA}} \cdot c_{\mathrm{mA}, \mathrm{i}}+p_{\mathrm{mi}} \cdot\left(c_{\text {cation, mi,i }}+c_{\text {anion, mi,i }}\right)\right)=\frac{J_{\text {ion, } \mathrm{i}}}{\delta_{\text {elec }}}+\frac{M}{\tau_{\text {elec }}}\left(c_{\mathrm{mA}, \mathrm{i}}-c_{\mathrm{mA}, \mathrm{i}-1}\right) .
$$

where $\tau_{\text {elec }}$ is the superficial residence time in the electrode due to convective flow of solution through the electrode. The residence time $\tau_{\text {elec }}$ is given by the total electrode volume $V_{\text {elec }}$ divided by the electrode flow rate $\Phi_{\text {elec }}$. This leakage flow of water is calculated as follows. The total water flow rate per cell is $\Phi_{\text {tot }}$, and the fraction of that which runs through an electrode is $\Phi_{\text {elec }}=\alpha \cdot \Phi_{\text {tot }}$, and thus the flow directed through the spacer channel is $\Phi_{\mathrm{sp}}=(1-2 \alpha) \cdot \Phi_{\text {tot. }}{ }^{44}$ The flows through the spacer channel and through the two electrodes are combined into the effluent which leaves the cell, and of this mixture the salt concentration, $c_{\text {eff, }}$ is given theoretically by $c_{\text {eff }}=(1-2 \alpha) \cdot c_{\mathrm{sp}, \mathrm{M}}+2 \alpha \cdot c_{\mathrm{mA}, \mathrm{M}}$, see Fig. 5

Finally we describe how to model the structure of the EDLs in the electrodes. As discussed in the previous section we will use a "modified Donnan model" which describes the micropores in the carbon particle by a single electrostatic potential. The concentration of ion $j$ in the micropore volume is then given by

$c_{\mathrm{j}, \mathrm{mi}}=c_{\mathrm{mA}} \cdot \exp \left(-z_{\mathrm{j}} \cdot \Delta \phi_{\mathrm{d}}+\mu_{\mathrm{att}}\right)$

where $z_{\mathrm{j}}=+1$ for the cation and $z_{\mathrm{j}}=-1$ for the anion, while $\mu_{\text {att }}$ is an attractive contribution to the ion chemical potential upon going from the macropores into the micropores, and $\Delta \phi_{d}$ is the Donnan potential difference between inside the porous carbon particle and outside, i.e., in the macropores. 
Micropore charge $c_{\text {charge,mi }}$ relates to the Stern layer potential drop across an inner layer separating the ion-containing electrolyte in the micropores, from the carbon itself in which the electron charge is stored, according to

$C_{\text {charge,mi }} \cdot h_{\mathrm{p}, \mathrm{mi}} \cdot F=-V_{\mathrm{T}} \cdot \Delta \phi_{\mathrm{St}} C_{\mathrm{St}}$.

where $h_{p, m i}$ is the volume/area ratio for the micropores. ${ }^{21}$ An important modification that we make relative to classical Donnan models, is to consider that even without applying a voltage (without electronic charge stored in the carbon) there is already a non-zero salt adsorption in the carbon particles. This effect we describe by considering a contribution to the chemical potential, $\mu_{\text {att }}$, of each ion upon entering the carbon particle, which for simplicity we take equal for each ion in the present work. This finalizes the cell model as will be used both for CDI and MCDI, both with ion release at zero voltage (0-MCDI) and for ion release at reversed voltage ( $r-M C D I)$.

\section{Results and Discussion}

\section{Testing of the modified Donnan model using equilibrium data for charge and salt adsorption in CDI}

In this section, we re-analyze equilibrium data for charge $\Sigma$ and salt adsorption $\Gamma_{\text {salt }}$ as presented in Fig. 2 in ref. 20 (defined in mol per gram of all electrodes, see note 56). These are equilibrium data, so the full cell potential $V_{\text {cell }}$ that is applied between the two electrodes only has contributions from Donnan and Stern potentials, $\Delta \phi_{\mathrm{d}}$ and $\Delta \phi_{\mathrm{S}}$, without potential gradients due to transport. $\Sigma$ and $\Gamma_{\text {salt }}$ are measured at a certain voltage $V_{\text {cell }}$ after first equilibrating the cell at zero voltage (using a shorted electrical circuit) by flowing the aqueous solution to be tested through the cell for a sufficient time $(\sim 1 \mathrm{hr})$. Charge $\Sigma$ is taken as a positive number. Details of the measurement of $\Sigma$ and $\Gamma_{\text {salt }}$ from the current and effluent salt concentration are given in ref. 20.

In Fig. $2 b$ we present data from ref. 20 for the ratio of $\Gamma_{\text {salt }} / \Sigma$ which is the charge efficiency of the $\mathrm{CDI}$-cell, $\Lambda$. These are direct data without making any model assumption. In Fig. 2a we show a novel representation of the data for $\Sigma$ and $\Gamma_{\text {salt }}$, namely by plotting the counterion and coion concentration in the carbon micropore volume. To derive these data, symmetry of the two electrodes must be assumed, i.e., that the cell voltage can be divided by two and then equals the voltage drop across each $E D L$ in each electrode, i.e., $V_{\text {cell }} /\left(2 \cdot V_{T}\right)=\Delta \phi_{d}+\Delta \phi_{S t}$. Also the theoretical lines in Fig. 2 are based on the assumption of symmetry.

How can we derive from the measured equilibrium charge $\Sigma$ and salt adsorption $\Gamma_{\text {salt, }}$, the counterion concentration, $c_{\text {counter,mi, }}$, and co-ion concentration, $c_{\mathrm{co}, \mathrm{mi}}$, in the micropores? To this end we use the fact that $\Gamma_{\text {salt }}$ depends on the summation of counterion and coion micropore concentration, while charge $\Sigma$ depends on the difference between these two concentrations. The counterion and coion micropore concentrations can then be calculated from

$c_{\text {counter,mi }}-c_{\text {counter,mi }}^{0}=\left(\Gamma_{\text {salt }}+\Sigma\right) \cdot \rho_{\mathrm{e}} / p_{\mathrm{mi}}, c_{\mathrm{co}, \mathrm{mi}}-c_{\mathrm{co}, \mathrm{mi}}^{0}=\left(\Gamma_{\text {salt }}-\Sigma\right) \cdot \rho_{\mathrm{e}} / \rho_{\mathrm{mi}}$.

where superscript " 0 " refers to the ion concentration at a cell voltage of $V_{\text {cell }}=0$, and where $\rho_{\mathrm{e}}$ is the overall electrode mass density (for which we use $\rho_{e}=0.58 \mathrm{~g} / \mathrm{ml}$ ) while we use a microporosity of $p_{\mathrm{mi}}=0.37$. Data from Fig. 2 in ref. 20 are converted using Eq. 13 and presented in Fig. $2 \mathrm{a}$ as volumetric 
concentrations per unit micropore volume. In Fig $2 b$ we show data for charge efficiency, $\Lambda$, which in the modified Donnan model assuming equal values of $\mu_{\text {att }}$ for both ions relates to the Donnan potential $\Delta \phi_{\mathrm{d}}$ according to

$\Lambda=\frac{\Gamma_{\text {salt }}}{\Sigma}=\tanh \frac{\Delta \phi_{\mathrm{d}}}{2}$.

To fit the modified Donnan model to the data, we first of all set the value of $h_{\mathrm{p}, \mathrm{mi}}$ (the volume/area ratio in the micropores) arbitrarily to $h_{\mathrm{p}, \mathrm{mi}}=1 \mathrm{~nm}$. This is possible because we will use $C_{\mathrm{St}}$ as an adjustable parameter, and as Eq. 12 shows, it is actually the ratio $C_{\mathrm{St}} / h_{\mathrm{p}, \mathrm{mi}}$ which is a single adjustable parameter, representing a volumetric capacity. For the Stern capacity, $C_{\mathrm{St}}$, we use the empirical expression $C_{\mathrm{St}}=C_{\mathrm{St}, 0}+\alpha \cdot \Delta \phi_{\mathrm{St}}^{2}$, with $C_{\mathrm{St}, 0}=0.12 \mathrm{~F} / \mathrm{m}^{2}$ (close to values derived in previous work, refs. $15,20,32$ ) and with $\alpha=5 \cdot 10^{-5} \mathrm{~F} / \mathrm{m}^{2}$ chosen such that $C_{\mathrm{St}}$ increases to $\sim 0.15 \mathrm{~F} / \mathrm{m}^{2}$ at the highest cell voltages considered. This second term can be rationalized as indicating that for higher Stern layer voltages (thus higher charge), the closest-approach-distance of the ion to the electron slightly decreases, which can be explained by the higher attractive force that acts across the Stern layer at high charge ${ }^{57,58} \mathrm{Be}$ cause of this second term, the fit of the modified Donnan model to the data improves. Finally, to fit the modified Donnan model to the data we set the attractive term to $\mu_{\text {att }}=2.0 \mathrm{kT}$.

As discussed in the previous section, using these parameter settings it is possible to describe the data quite accurately by the modified Donnan model, see Fig. 2 . The observed very negative co-ion expulsions are well reproduced. Note that in Fig. 2a micropore concentrations are given, relative to the ion concentrations at zero cell voltage, which at this condition are given by $c_{\mathrm{Vcell}=0}=c_{\infty} \cdot \exp \left(\mu_{\text {att }}\right)$, i.e., $C_{\mathrm{V} c e l l}=0=37 \mathrm{mM}$ and $148 \mathrm{mM}$ for $c_{\infty}=5 \mathrm{mM}$ and $20 \mathrm{mM}$, respectively. Also the charge efficiency, $\Lambda$, as presented in Fig. $2 \mathrm{~b}$ as function of cell voltage and ionic strength, is well described. Thus, the modified Donnan model is a suitable description for ion storage in the micropores of porous activated carbon electrode, and can be used to describe the EDL-structure in a full (M)CDI transport model.

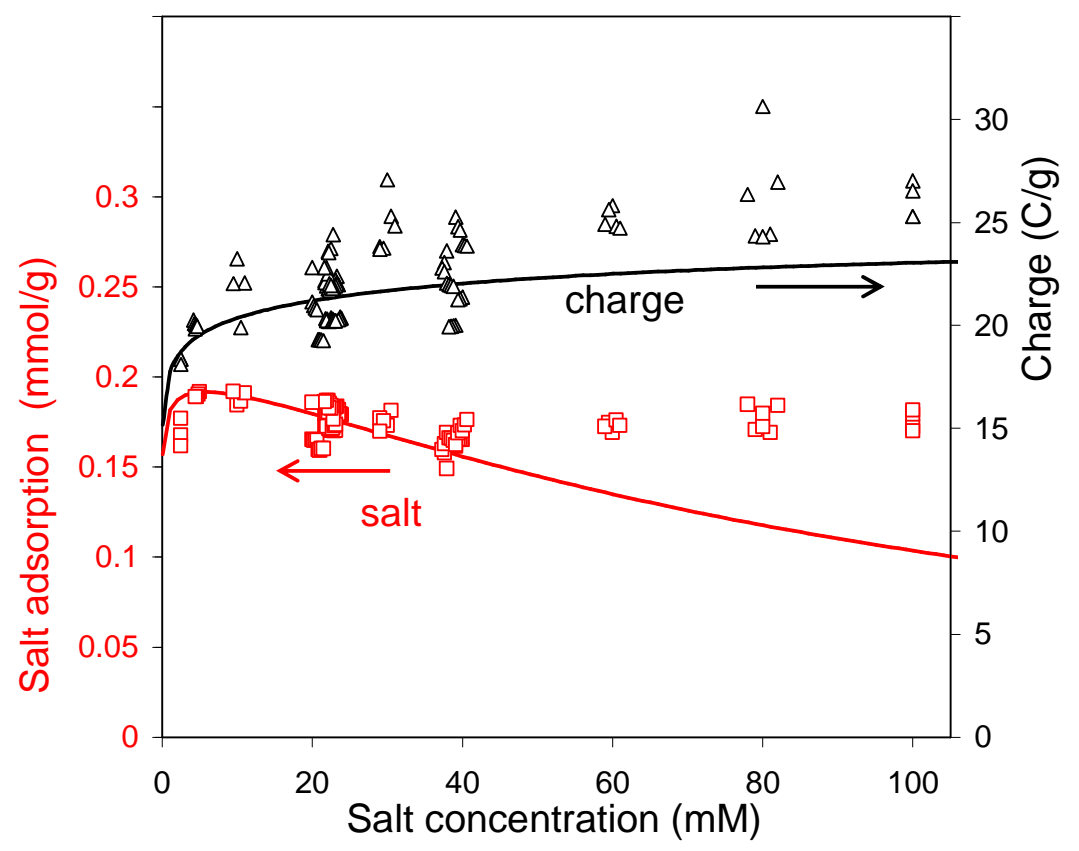

Fig. 3. Data and equilibrium theory for salt adsorption and charge (per gram of all electrodes) in CDI as function of salt concentration (half-cycle time $500 \mathrm{~s}, V_{\text {cell }}=1.2 \mathrm{~V}$ ). Model parameters as in Fig. 4. 
In Fig. 3 we compare the Donnan model with new data reporting the influence of salt concentration for a larger range, and not for salt adsorption for the duration of $1 \mathrm{hr}$ as in ref. 20, but for a duration of each phase in the cycle (the "half-cycle time", HCT) of only $500 \mathrm{~s}$, which is just enough to approach equilibrium, see Fig. 4. Also the material that is used in the present study is from a different batch than used in ref. 20, which notably is thicker $(\sim 360 \mu \mathrm{m}$ vs $270 \mu \mathrm{m})$. To fit the data in Fig. 3 we use slightly different values for $p_{\text {mi }}$ and $\mu_{\text {att, }}$, namely $p_{\text {mi }}=0.30$ and $\mu_{\text {att }}=1.4 \mathrm{kT}$, while $\rho_{\mathrm{e}}=0.55 \mathrm{~g} / \mathrm{ml}$. These values are also used in Figs. 4 and 5. Fig. 3 shows that up to concentrations of $c_{\text {salt }}=40 \mathrm{mM}$ the model describes the data well. In Fig. 3, charge is given in C/g which is equal to charge $\Sigma$ (which is expressed in $\mathrm{mol} / \mathrm{g}$ ), multiplied by Faraday's number, $F$.

\section{Experimental setup and parameter settings for transport modeling of $(M) C D I$}

Experimental details of our (M)CDI test stack have been described in refs. 20,32,44,46. In brief, $N=8$ cells as depicted in Fig. 1 are assembled from current collectors, electrodes, ion-exchange membranes and spacers. Each current collector is used in two adjacent cells (one above, and one below). Therefore, for MCDI it is important to reverse the sequence of ion-exchange membranes from cell to cell because the cathode and anode are also reversed. The salt solution flows from outside the stack on all four sides into the square $6 \times 6 \mathrm{~cm}^{2}$ spacer channel of each of the $N$ cells, and leaves from a hole in the middle of each cell (area $1.5 \times 1.5 \mathrm{~cm}^{2}$ ). These are the dimensions of all layers. Thus, the projected area $A$ per electrode (membrane) is given by $A=33.8 \mathrm{~cm}^{2}$. Materials used are graphite current collectors (Cixi Sealing Spacer Material Factory, Ningbo City, China, thickness $\delta=250 \mu \mathrm{m}$ ), porous carbon electrodes (Materials \& Methods, $\mathrm{PACMM}^{\mathrm{TM}} 203$, Irvine, CA, $\delta_{\mathrm{e}}=362 \mu \mathrm{m}, m_{\mathrm{tot}}=10.75 \mathrm{~g}$ total mass in the stack), anion and cation exchange membranes ((Neosepta AMX, $\delta_{\text {mem }}=140 \mu \mathrm{m}$, and Neosepta CMX, $\delta_{\text {mem }}=170 \mu \mathrm{m}$, Tokuyama, Japan) and a polymer spacer (Glass fibre prefilter, Millipore, Ireland, $\delta_{\mathrm{sp}}=350 \mu \mathrm{m}$ ). After assembly, the entire stack of all layers is firmly pressed together and placed in a teflon housing. The salt concentration of the effluent is measured on-line via conductivity. The water flow rate per cell is given by $\Phi_{\text {tot }}=0.125 \mathrm{ml} / \mathrm{sec}$. The cell voltage is applied using a potentiostat which measures the current between cathode and anode after applying a step change in cell voltage. The current is integrated for the duration of the ion adsorption step, giving the total charge tranferred which is equal (within measurement error and for a small leakage current) to the charge released again in the ion-release step. This total charge with dimension Coulomb is divided by the total electrode mass, $m_{\mathrm{tot}}$, and by Faraday's number to obtain charge expressed in mol/gr as in Figs. 3 and 4. The effluent salt concentration is calculated from the measured conductivity, and the salt removal per total electrode mass, $\Gamma_{\text {salt, }}$ is derived from the first equality in Eq. 15 below. To calculate salt removal in the theoretical model, we use two methods: 1. Integration over time of the difference between the effluent concentration $c_{\text {eff }}$ and the inflowing concentration $c_{\text {in }}$, times the total water flowrate, $\Phi_{\text {tot }}$, like we do for the analysis of the data, or 2. Taking the difference in total salt storage in the cells between time $t_{1}$ and $t_{2}$. Mathematically, these two methods are expressed as:

$\Gamma_{\text {salt }}=\frac{N \Phi_{\mathrm{sp}}}{m_{\mathrm{tot}}} \int_{t_{1}}^{t_{2}}\left(c_{\text {eff }}-c_{\mathrm{in}}\right) \mathrm{d} t=\frac{N A}{m_{\mathrm{tot}} M}\left[\sum_{i=1}^{M}\left(\delta_{\mathrm{sp}} c_{\mathrm{sp}, \mathrm{i}}+2 \delta_{\text {elec }}\left(p_{\mathrm{mA}} c_{\mathrm{mA}}+\frac{1}{2} p_{\mathrm{mi}}\left(c_{\text {cation, }, \mathrm{mi}}+c_{\text {anion, mi }}\right)\right)\right)\right]_{t_{1}}^{t_{2}}$. 
Both experimentally and theoretically, when the 'dynamic steady state' is reached, the salt removal during the ion adsorption-step is equal to the release of salt in the desorption-step.

For the voltage drop across the spacer channel we take the average of the diffusion coefficients ${ }^{5}$ of $\mathrm{Na}^{+}$and $\mathrm{Cl}^{-}$, resulting in $16.8 \cdot 10^{-9} \mathrm{~m}^{2} / \mathrm{s}$. For the diffusion coefficient in the membrane we arbitrarily take $10 \%$ of the value of solution, thus $D_{\text {mem }}=1.68 \cdot 10^{-9} \mathrm{~m}^{2} / \mathrm{s}$. For the spacer and membrane thickness we take $\delta_{\mathrm{sp}}=250 \mu \mathrm{m}$ and $\delta_{\mathrm{mem}}=140 \mu \mathrm{m}$, while we use a membrane fixed charge density of $X=8 \mathrm{M}$. In the calculation, the number of stirred volumes placed in series, $M$, is set to $M=6$. The resistance $R_{\text {elec }}$ is set to $R_{\text {elec }}=0.12 \Omega . \mathrm{mol} / \mathrm{m}$. The leakage factor $\alpha$ is set to $0.25 \%$, i.e., through both electrode only $0.5 \%$ of the total water flow rate is directed.

\section{Comparison of theory with experiments for salt adsorption and charge in CDI and MCDI as function of cycle time}

In this section we discuss data where we accurately compare CDI with 0-MCDI (MCDI with ion release at zero cell voltage) and with r-MCDI (where ion release occurs at reversed voltage). Let us mention again that $r-C D I$ is not a feasible option, because ion release at reversed voltage in CDI would immediately lead to the just-released ions being adsorbed again, but now in the opposite electrode. Experimentally, $\mathrm{CDI}$ and 0-MCDI were previously compared by Kim and Choi, in ref. 33 for $V_{\text {cell }}=1.2 \mathrm{~V}$ and $c_{\text {salt }}=3.5 \mathrm{mM}$, in ref. 34 for $V_{\text {cell }}=1.5 \mathrm{~V}$ and $c_{\text {salt }}=3.5 \mathrm{mM}$, and in ref. 35 for $V_{\text {cell }}=1.2-1.6 \mathrm{~V}$ and $c_{\text {salt }}=17 \mathrm{mM}$. In all cases the half-cycle time to be defined below, was HCT=180 s. In refs. 33 and 34 only a cation-exchange membrane was placed in front of the cathode (without a membrane placed in front of the anode), while in ref. 35 both cation-exchange and anion-exchange membranes were used, in front of cathode and anode, respectively (just as in the present work). When going from CDI to $0-\mathrm{MCDI}$, the reported increase in salt removal per cycle was about $30 \%$ in ref. 33 , about $20 \%$ in ref. 34 , but was much higher in ref. 35 where the salt adsorption per cycle was reported to increase by at least $100 \%$ (see fig. 2 of ref. 35). This large increase may be related to the low current efficiency reported for CDI (i.e., CDI-performance may not have been optimal in these experiments).

Theoretically, 0-MCDI and r-MCDI were previously only briefly compared in ref. 32 (Fig. 5, $V_{\text {cell }}=1.4 \mathrm{~V}, C_{\mathrm{NaCl}}=36 \mathrm{mM}$ ) showing a predicted $\sim 20 \%$ increase in salt removal for $\mathrm{r}$-MCDI compared to 0 -MCDI. In the present work, we compare CDI with 0-MCDI and r-MCDI, both experimentally and theoretically. This will be done on the basis of data for $c_{\mathrm{NaCl}, \mathrm{in}}=20 \mathrm{mM}$ at a cell voltage of $V_{\text {cell }}=1.2 \mathrm{~V}$ and a flow rate of $\Phi_{\text {tot }}=0.125 \mathrm{ml} / \mathrm{s}$ per cell. The data are presented as function of the 'half-cycle time', HCT, i.e., the duration of an ion removal-step, which is equal to the duration of the subsequent ion-release step. Thus, the full cycle has a duration of twice the HCT. For application of (M)CDI in practice, it is important that HCT is optimized to maximize the average salt removal rate.

Fig. 4 shows first experimental data where CDI is compared with 0-MCDI and r-MCDI as function of HCT, showing that for long HCT the salt adsorption and charge level off, while for low HCT both tend to zero. Going from CDI to $0-\mathrm{MCDI}$ and to $\mathrm{r}-\mathrm{MCDI}$, we see that the salt removal increases in two about equal steps of $\sim 20 \%$, making r-MCDI about $40 \%$ more effective than CDI. For both MCDI-options we observe that the salt adsorption decreases again at long HCTs, but not for CDI. For charge we ob- 
serve that the plateau values are the same for CDI and 0-MCDI with a $20 \%$ increase in charge observed for r-MCDI.

Comparing theory with data, we find a very good agreement: first of all, we observe that the value of the plateaus at high HCT is well predicted, both for salt adsorption and for charge, and for each of the three process modes. We also find that in MCDI the predicted plateau-value in salt adsorption decreases slightly with $\mathrm{HCT}$, which is also observed in the data, though more evidently. In our model this decrease is due to the water flow behind the membrane (i.e., that $\alpha \neq 0$ ) and the membrane not being $100 \%$ ideally permselective. Because of these two effects, slowly the salt which is stored in the macropores leaks away (i.e., $c_{\mathrm{mA}}$ goes down in time). The decline in salt adsorption and charge when HCT goes to zero is also well reproduced for all three process options. Fig. 5 shows experimental data and theoretical predictions for the effluent concentration as function of time, for one value of the halfcycle time, namely $\mathrm{HCT}=300 \mathrm{~s}$. As can be observed the predicted curves are quite similar to the experimental ones, certainly for $\mathrm{CDI}$ and 0-MCDI. For r-MCDI the minimum in effluent salt concentration occurs a bit later in theory than in the experiment, and is deeper, while the maximum (upon voltage reversal) is higher, and the decline in $c_{\text {eff }}$ is more rapid than experimentally.

Finally, Fig. 6 shows the predicted development of the macropore concentration, $c_{\mathrm{mA}}$, as function of time, showing the very marked differences between CDI, 0-MCDI and r-MCDI. For both MCDI-options, the macropore concentration, $c_{\mathrm{mA}}$, goes up during ion adsorption while it goes down for CDI, explaining the higher ion adsorption capacity for MCDI vs CDI.

In conclusion, in this work we have made significant progress in setting up a comprehensive model which can describe both $\mathrm{CDI}$ and MCDI, with ion release at zero voltage as well as at reversed voltage. Important is consideration of the macropore volume, where the cation concentration equals that of the anions, as well as the use of the modified Donnan model for charge and salt storage in the micropores within the carbon particles.
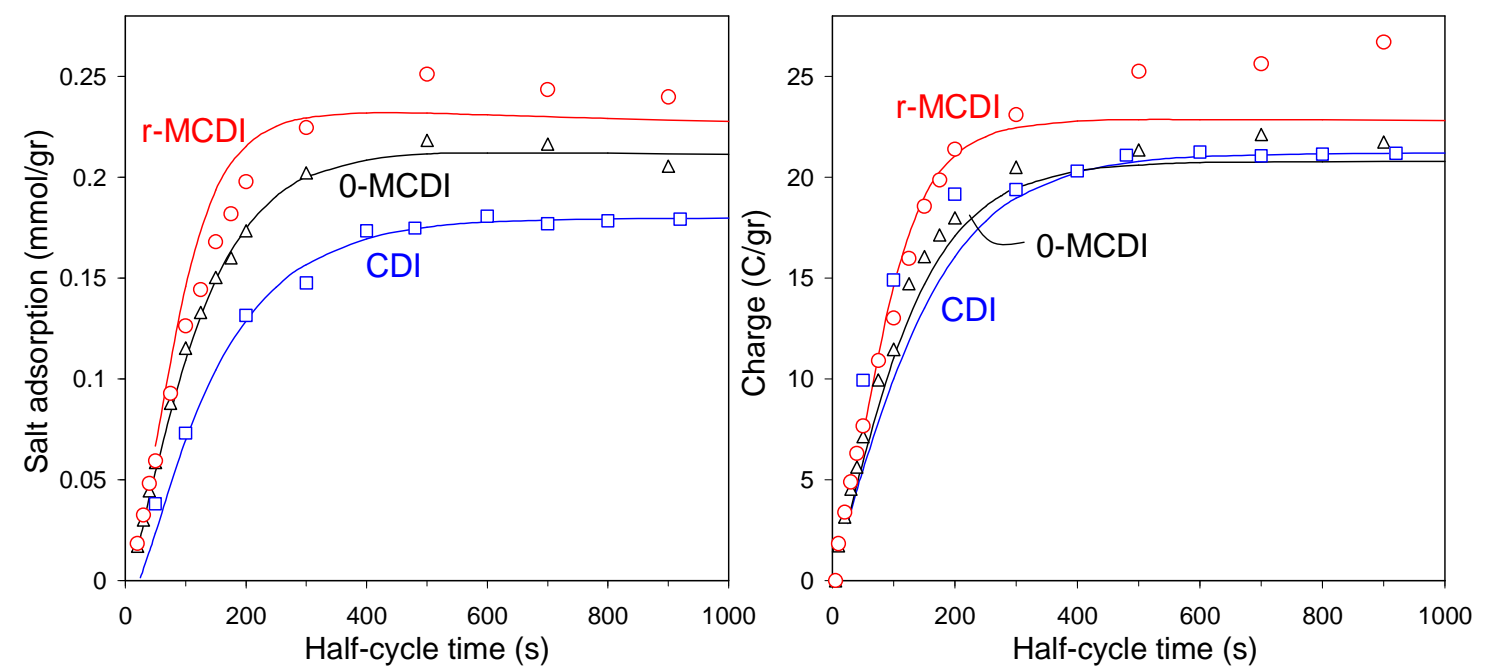

Fig. 4. Salt adsorption and charge in CDI (squares), 0-MCDI (triangles), and r-MCDI (circles) as function of half-cycle time $\left(c_{\text {salt,in }}=20 \mathrm{mM}, V_{\text {cell }}=1.2 \mathrm{~V}\right)$. 

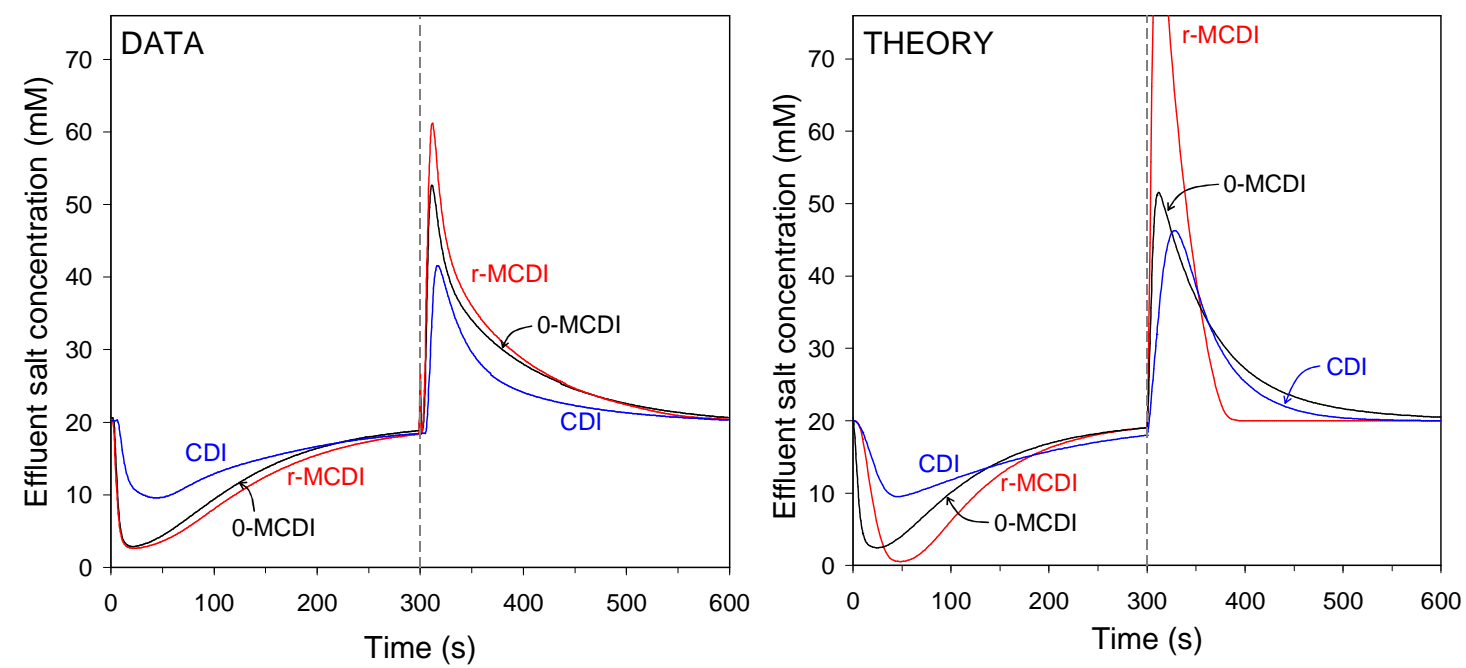

Fig. 5. Comparison of experimental data and theoretical model for CDI, 0-MCDI, and r-MCDI, for a half-cycle time of $300 \mathrm{sec}\left(c_{\text {salt,in }}=20 \mathrm{mM}, V_{\text {cell }}=1.2 \mathrm{~V}\right)$.

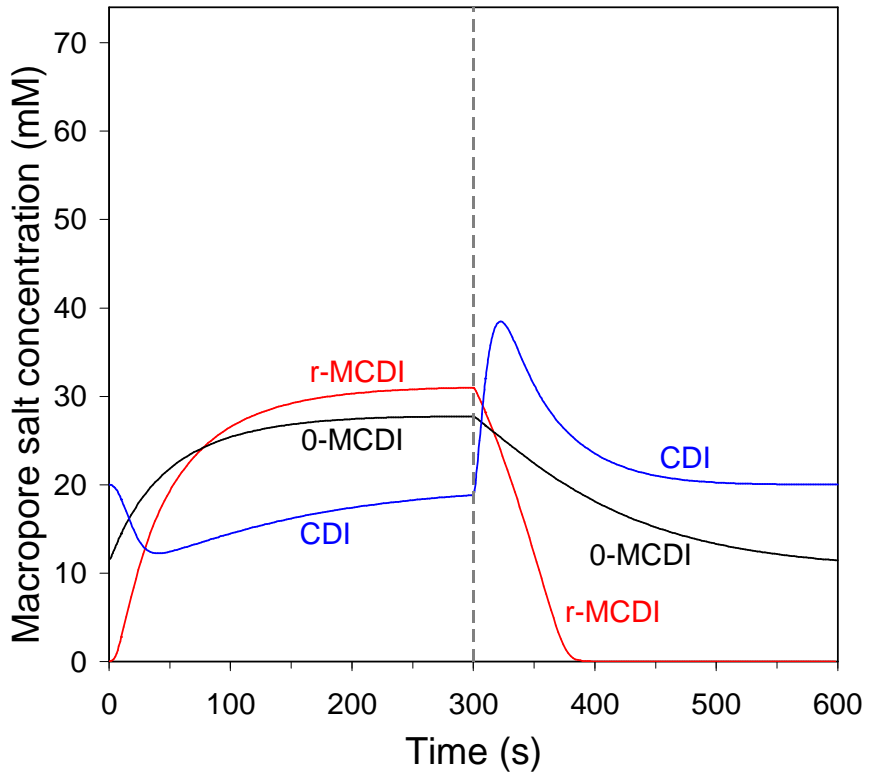

Fig. 6 Theoretical prediction for macropore salt concentration for CDI, 0-MCDI, and r-MCDI $\left(4^{\text {th }}\right.$ stirred volume out of the total of $N=6$ ), for conditions as in Fig. 5.

\section{Conclusions}

We have set up a comprehensive model which describes both capacitive deionization (CDI) and membrane capacitive deionization (MCDI). For MCDI two operation modes are considered, either "0-MCDI" where ions are release at zero cell voltage, and "r-MCDI" where the ions are release at reversed voltage. Experiments and modeling agree that 0-MCDI removes around $20 \%$ more salt than $\mathrm{CDI}$, and r-MCDI again 20\% more. The model includes several novel elements, such as including the fact that also co-ions can pass the ion-exchange membrane, while for the electrode, a distinction is made between the transport pathways, or macropores, where the concentration of both ions is the same, and the micropores inside carbon particles where charge is stored and thus the ion concentrations can be different. For the micropores a novel modified Donnan model is implemented which very favorably describes equilibrium data for salt adsorption and charge. An ion transport resistance in the electrode was included by considering a resistance which is inversely proportional to the macropore 
salt concentration. Major trends in salt adsorption and charge as function of the duration of the (M)CDI-cycle are well reproduced by the theory, as well as the profiles of effluent concentration vs. time. The validated MCDI process model can be used for design and process optimization studies.

\section{Acknowledgements}

This work was performed in the TTIW-cooperation framework of Wetsus, Centre of Excellence for Sustainable Water Technology (www.wetsus.nl). Wetsus is funded by the Dutch Ministry of Economic Affairs, the European Union Regional Development Fund, the Province of Friesland, the City of Leeuwarden and the EZ/Kompas program of the 'Samenwerkingsverband Noord-Nederland'.

\section{References}

1. M.A. Shannon, P.W. Bohn, M. Elimelech, J.G. Georgiadis, B.J. Mariñas, and A.M. Mayes, Nature 452, 301 (2008).

2. R. Semiat, Env. Sci. Techn. 42, 8193 (2008).

3. Q. Schiermeier, Nature 452, 260 (2008).

4. J.R. Wilson, Demineralization by Electrodialysis, Butterworths (1960).

5. A.A. Sonin and R.F. Probstein, Desalination 5, 293 (1968).

6. G.W. Murphy and D.D. Caudle, Electrochimica Acta 121655 (1967).

7. A.M. Johnson and J. Newman, J. Electrochem. Soc. 118510 (1971).

8. Y. Oren and A. Soffer, J. Appl. Electrochem. 13473 (1983).

9. J.C. Farmer, D.V. Fix, G.V. Mack, R.W. Pekala, and J.F. Poco, J. Electrochem. Soc. 143159 (1996).

10. C.J. Gabelich, T.D. Tran, and I.H. Mel Suffet, Env. Sci. Techn. 363010 (2002).

11. T.J. Welgemoed and C.F. Schutte, Desalination 183327 (2005).

12. P. Xu, J.E. Drewes, D. Heil, and G. Wang, Water Research 422605 (2008).

13. P.M. Biesheuvel, J. Colloid Interface Sci. 332258 (2009).

14. K.C. Leonard, J.R. Genthe, J.L. Sanfilippo, W.A. Zeltner, and M.A. Anderson, Electrochimica Acta 545286 (2009).

15. P.M. Biesheuvel, B. van Limpt, and A. van der Wal, J. Phys. Chem. C. 1135636 (2009).

16. M. Noked, E. Avraham, A. Soffer, and D. Aurbach, J. Phys. Chem. C 11321319 (2009).

17. Y. Bouhadana, E. Avraham, A. Soffer, and D. Aurbach, AlChE J. 56779 (2010).

18. M.A. Anderson, A.L. Cudero and J. Palma, Electrochim. Acta 553845 (2010).

19. S.-J. Seo, H. Jeon, J. Kwang Lee, G.-Y. Kim, D. Park, H. Nojima, J. Lee, and S.-H. Moon, Water Research 442267 (2010).

20. R. Zhao, P.M. Biesheuvel, H. Miedema, H. Bruning, and A. van der Wal, J. Phys. Chem. Lett. 1 205 (2010).

21. P.M. Biesheuvel and M.Z. Bazant, Phys. Rev. E 81031502 (2010).

22. H. Li, L. Zou, L. Pan, and Z. Sun, Env. Sci. \& Techn. 448692 (2010).

23. J. Biener, M. Stadermann, M. Suss, M.A. Worsley, M.M. Biener, K.A. Rose and Th.F. Baumann, Energy \& Env. Sci. 4656 (2011). 
24. P. Simon and Y. Gogotsi, Nature Materials 7, 845 (2008).

25. M.D. Levi, G. Salitra, N. Levy, D. Aurbach, and J. Maier, Nature Materials 8872 (2009).

26. I.B. Sprague and P. Dutta, Num. Heat Transfer, Part A 591 (2011).

27. Y. Bouhadana, M. Ben-Tzion, A. Soffer, and D. Aurbach, Desalination 268253 (2011).

28. P.M. Biesheuvel, Y. Fu and M.Z. Bazant, Phys. Rev. E, submitted (2011).

29. M.D. Andelman, Can. Patent CA 2444390 (2002).

30. J.-B. Lee, K.-K. Park, H.-M. Eum, and C.W. Lee, Desalination 196125 (2006).

31. H. Li, Y. Gao, L. Pan, Y. Zhang, Y. Chen, and Z. Sun, Water Research 424923 (2008).

32. P.M. Biesheuvel and A. van der Wal, J. Membrane Sci 346256 (2010).

33. Y.-J. Kim and J.-H. Choi, Water Research 44990 (2010).

34. Y.-J. Kim and J.-H. Choi, Sep. Purif. Techn. 7170 (2010).

35. Y.-J. Kim, J. Hur, W. Bae, and J.-H. Choi, Desalination 253119 (2010).

36. M. Yaniv and A. Soffer, J. Electrochem. Soc. 123506 (1976).

37. P. Leroy, A. Revil and D. Coelho, J. Colloid Interface Sci. 296248 (2006).

38. M.A. Murad and C. Moyne, Comput. Geosci. 1247 (2008).

39. R. Schlögl, Stofftransport durch Membranen, Band 9 of "Fortschritte der Physikalischen Chemie", Darmstadt (1964).

40. A.Szymczyk, H. Zhu, and B. Balannec, Langmuir 26, 1214 (2010).

41. P.M. Biesheuvel, J. Colloid Interface Sci. 355389 (2011).

42. V.G. Levich, Physicochemical Hydrodynamics, Prentice-Hall (1962).

43. S. Mafé, J. Pellicer, and V.M. Aguilella, J. Phys. Chem. 906045 (1986).

44. B.B. Sales, M. Saakes, J.W. Post, C.J.N. Buisman, P.M. Biesheuvel, and H.V.M. Hamelers, Env. Sci. \& Techn. 445661 (2010).

45. D. Brogioli, Phys. Rev. Lett. 103, 058501 (2009).

46. D. Brogioli, R. Zhao, and P.M. Biesheuvel, Energy \& Env. Science 4772 (2011).

47. K.-L. Yang, T.-Y. Ying, S. Yiacoumi, C. Tsouris, and E.S. Vittoratos, Langmuir 171961 (2001).

48. C.-H. Hou, P. Taboada-Serrano, S. Yiacoumi, and C. Tsouris, J. Chem. Phys. 129224703 (2008).

49. N. Boon and R. van Roij, Mol. Phys., 109 accepted (2011). DOI:10.1080/00268976.2011.554334

50. P.M. Biesheuvel, J. Phys.: Condens. Matter 16 L499 (2004).

51. M. Muller, B. Kastening J. Electroanal. Chem. 374149 (1994).

52. M.D. Levi, S. Sigalov, G. Salitra, R. Elazari, and D. Aurbach, J. Phys. Chem. Lett. 2120 (2011).

53. F.G. Helfferich, Ion Exchange, Dover (1962).

54. K.J. Vetter, Electrochemical Kinetics, Academic Press (1967).

55. M.Z. Bazant, K. Thornton, and A. Ajdari, Phys. Rev E 70021506 (2004).

56. Note that the numbers given in Fig. 2 of ref. 18 must be multiplied by 10.6/8.0 because in the experiment there was actually 8.0 gram of dry electrode mass instead of 10.6 gram.

57. D.C. Grahame, Chem. Rev. 41441 (1947).

58. M.Z. Bazant, K.T. Chu, and B.J. Bayly, SIAM J. Appl. Math. 651463 (2005). 